\title{
3 Tesla Apparent Diffusion Coefficient (ADC) Values of Thyroid Nodules: Prediction of Benignancy and Malignancy
}

\author{
Selen Bayraktaroglu ${ }^{1,}$, , Pınar Karakan Öztürk ${ }^{2}$, Naim Ceylan ${ }^{1}$, Özer Makay ${ }^{3}$, Gökhan İçöz ${ }^{3}$ and Yeşim \\ Ertan $^{4}$ \\ ${ }^{1}$ Department of Radiology, Ege University Hospital, Bornova, Izmir, Turkey \\ ${ }^{2}$ Department of Radiology, Manisa State Hospital, Manisa, Turkey \\ ${ }^{3}$ Department of General Surgery, Ege University Hospital, Bornova, Izmir, Turkey \\ ${ }^{4}$ Department of Pathology, Ege University Hospital, Bornova, Izmir, Turkey \\ "Corresponding author: Department of Radiology, Ege University Hospita, Bornova, Izmir, Turkey. Email: selenb2000@gmail.com
}

Received 2017 November 12; Revised 2019 April 02; Accepted 2019 April 07.

\begin{abstract}
Background: High field strength magnets have the potential to provide good quality diffusion weighted imaging (DWI) sequence images and apparent diffusion coefficient (ADC) maps can give important data for differential diagnosis of thyroid nodules.

Objectives: To determine the sensitivity and specificity of ADC values of malignant and benign thyroid nodules at 3 Tesla ( $T$ ) magnetic resonance imaging (MRI) and to correlate imaging findings with histopathologic results.

Patients and Methods: Thirty two patients and 20 healthy volunteers were enrolled in the study. DWI was acquired with b values of 500 and 1000. Mean apparent diffusion coefficient values ( $\mathrm{ADC}_{\mathrm{MEAN}}$ ) of the nodules and thyroid parenchyma were measured. Nodule $\mathrm{ADC}_{\mathrm{MEAN}} /$ thyroid parenchymal $\mathrm{ADC}_{\mathrm{MEAN}}$ ratio were calculated for each nodule in 25 patients.

Results: Thirteen malignant and 63 benign nodules were analysed. The $\mathrm{ADC}_{\mathrm{MEAN}}$ values of malignant nodules were significantly lower than benign nodules in each $b$ value $(\mathrm{P}<0.0001)$. Nodular $\mathrm{ADC}_{\text {MEAN }} /$ thyroid parenchymal $\mathrm{ADC}_{\text {MEAN }}$ ratio was significantly lower in the malignant group at b:500 and b:1000 $(\mathrm{P}<0.0001)$. Considering the selected cut off values $(0.98$ for b:500 and 0.95 for b:1000) this ratio showed the best performance in differentiation of malignant and benign nodules with a sensitivity of $100 \%$ and specificity of $92 \%-100 \%$.

Conclusion: DWI with quantitative ADC measurements is useful in the differentiation of benign and malignant thyroid nodules. The nodule $\mathrm{ADC}_{\mathrm{MEAN}} /$ thyroid parenchyma $\mathrm{ADC}_{\mathrm{MEAN}}$ ratio can be used as an adjunctive parameter in differentiation.
\end{abstract}

Keywords: Thyroid, Nodular Disease, Diffusion Weighted Imaging, ADC Ratio

\section{Background}

Nodular disease of thyroid gland is a common clinical problem. With the increasing use of ultrasonography, the detection rate has also increased. The prevalence of nodules detected in population during physical examination is $4 \%-7 \%$ and $10 \%-40 \%$ during ultrasonographic evaluation $(1,2)$. Approximately $5 \%$ of these nodules are malignant $(3,4)$. The primary aim of imaging modalities is to detect these malignant nodules.

The traditional evaluation of thyroid nodules includes physical examination, thyroid function tests, ultrasonography and scintigraphy. However, these methods can not reliably differentiate benign nodules from the malignant ones. Fine-needle aspiration biopsy (FNAB) is an efficient method but it has limitations $(5,6)$. Conventional $\mathrm{T} 1$ and T2 weighted sequences used in magnetic resonance imag- ing (MRI) also have limited value in differential diagnosis.

Diffusion-weighted MRI imaging (DWI) and the quantitative parameter, apparent diffusion coefficient (ADC) derived from it are used for evaluation of microscopic water diffusion percentage in tissues. Clinically, the most common application of DWI is in early recognition of cerebral infarction (7). However, its clinical applications have increased rapidly and DWI has been used in the evaluation of tumors. Studies in the head and neck region have shown that DWI can provide information in the characterization of tumors, cervical lymphadenopathies, and thyroid nodules (8-12). In recent years, several authors have shown that 1.5 Tesla $(\mathrm{T})$ diffusion-weighted MRI imaging can give important data for differential diagnosis of thyroid nodules (2, 8-10). Recently, 3 T MR imaging is widely used clinically and has a higher signal to noise ratio. These high field strength magnets have the potential to provide better 
quality DWI image and ADC maps. Therefore, it is important to investigate how the ADC values of the norrnal thyroid gland, benign and malignant thyroid nodules vary in 3 T MR scanners. In literature, there are a limited number of studies related to DWI characteristics of thyroid nodules in 3 Tesla scanners $(13,14)$.

\section{Objectives}

The purpose of our study was to evaluate the clinical utility of 3 Tesla ADC values and normalized ADC ratios (nodule $\mathrm{ADC}_{\mathrm{MEAN}}$ /thyroid paranchymal $\mathrm{ADC}_{\mathrm{MEAN}}$ ratio) in differentiation between malignant and benign thyroid nodules and to compare these results with histopathological examinations.

\section{Patients and Methods:}

\subsection{Patients and Control Group}

In this prospective study, 32 patients who were candidates of surgery ( 20 women, 12 men, age range: $28-73$, mean age: 52 ) were included. All patients had sonographically detected either solitary or multiple thyroid nodules. The participants were selected from the patients that were admitted to the General Surgery Department of our institution from November 2010 to March 2011. The study protocol was approved by the Local Ethics Committee. Informed consent was obtained before the examination. Patients with a history of FNAB within 3 weeks were excluded from the study. All patients were evaluated sonographically (Antares, Siemens, Erlangen, Germany) prior to MRI examination and patients with purely cystic nodules and nodules with a diameter smaller than $1 \mathrm{~cm}$ were excluded.

Twenty subjects without a known thyroid disease and who had undergone neck MR studies (11 male, nine female, mean age: 30 ) were also enrolled in the study.

\subsection{MRI Protocol}

MRI studies were performed with a high performance gradient of 3 Tesla MRI system (maximum gradient strength of $40 \mathrm{mT} / \mathrm{m}$ and the maximum slow rate in sec $200 \mathrm{mT} / \mathrm{m}$ ) (Verio, Siemens, Erlangen, Germany). Fourchannel phased-array neck coil was used.

The MRI protocol included: Turbo Spin Echo (TSE) T1 axial (repetition time [TR]/echo time [TE] 493/9.6, flip angle 150 degrees, number of excitation [NEX]: 2 , matrix $384 \times$ 257, field of view [FOV] $23 \mathrm{~cm}$, slice thickness $5 \mathrm{~mm}$, intersection gap $0 \mathrm{~mm}$ ), T2 axial (TR/TE 3740/89, flip angle 150 degrees, NEX: 2, matrix $384 \times 257$, FOV $23 \mathrm{~cm}$, slice thickness $5 \mathrm{~mm}$, intersection gap $0 \mathrm{~mm}$ ) and sagittal short tau inversion recovery [STIR] (TR/TE 4000/57, flip angle of 150 degrees, NEX: 2, matrix $320 \times 240$, FOV of $22 \mathrm{~cm}$, slice thickness $5 \mathrm{~mm}$; sectional width $1 \mathrm{~mm}$, generalized autocalibrating partially parallel acquisitions [GRAPPA] factor 2) sequences.

DWI was acquired using a single shot spin echo echoplanar imaging (EPI) sequence, diffusion gradients were applied in three orthogonal directions simultaneously. Multiple axial scans covering the thyroid gland was acquired. Imaging parameters were as follows: TR/TE: 13200/75, matrix: $128 \times 128$, slice thickness: 4 mm, NEX: 2 , FOV: $23 \mathrm{~cm}$, bandwidth $1500 \mathrm{~Hz} / \mathrm{px}$. Spectral fat saturation (spectral attenuated inversion recovery [SPAIR]) was added to diffusion imaging and parallel imaging (GRAPPA factor: 2)algorithm was used. Diffusion weighted MR images were acquired with a pair of diffusion factors (b factor): 0 and $500 \mathrm{~s} / \mathrm{mm}^{2}$ and 0 and $1000 \mathrm{~s} / \mathrm{mm}^{2}$. The ADC maps were calculated for these $b$ values.

\subsection{MR Data Analysis}

A radiologist specialized in head and neck radiology interpreted the ADC measurements. ADC values were measured using a separate workstation (Leonardo workstation, Siemens). One patient was excluded from the study due to image distortion caused by susceptibility artifact.

Nodular localization, internal structure, and size were determined using sagittal T2-weighted and STIR images. Cystic and hemorrhagic areas of nodules were determined and ADC measurement of these areas was avoided. Smallest standard $\left(0.16 \mathrm{~cm}^{2}\right)$ region of interest (ROI) was used to measure ADC values of nodules. Three different ROI measurements were applied for each ADC value measurement and the average of ADC values were calculated to determine the minimum, mean and maximum ADC values. ADC values were measured from the normal parenchyma of the thyroid gland in patients and in the control group as well. The intact thyroid parenchyma could not be detected in five patients with multinodular thyroid disease. The mean parenchymal ADC values of three patients with histopathological diagnosis of thyroiditis were excluded from the evaluations.

Thyroidectomy was performed for all patients. A pathologist who was blinded to MRI findings analysed the resected surgical material. Surgery was performed within one week after MR imaging. The histopathological results were correlated with the ADC values.

The flowchart provides information about the method of patient recruitment and data analysis (Figure 1 ). 


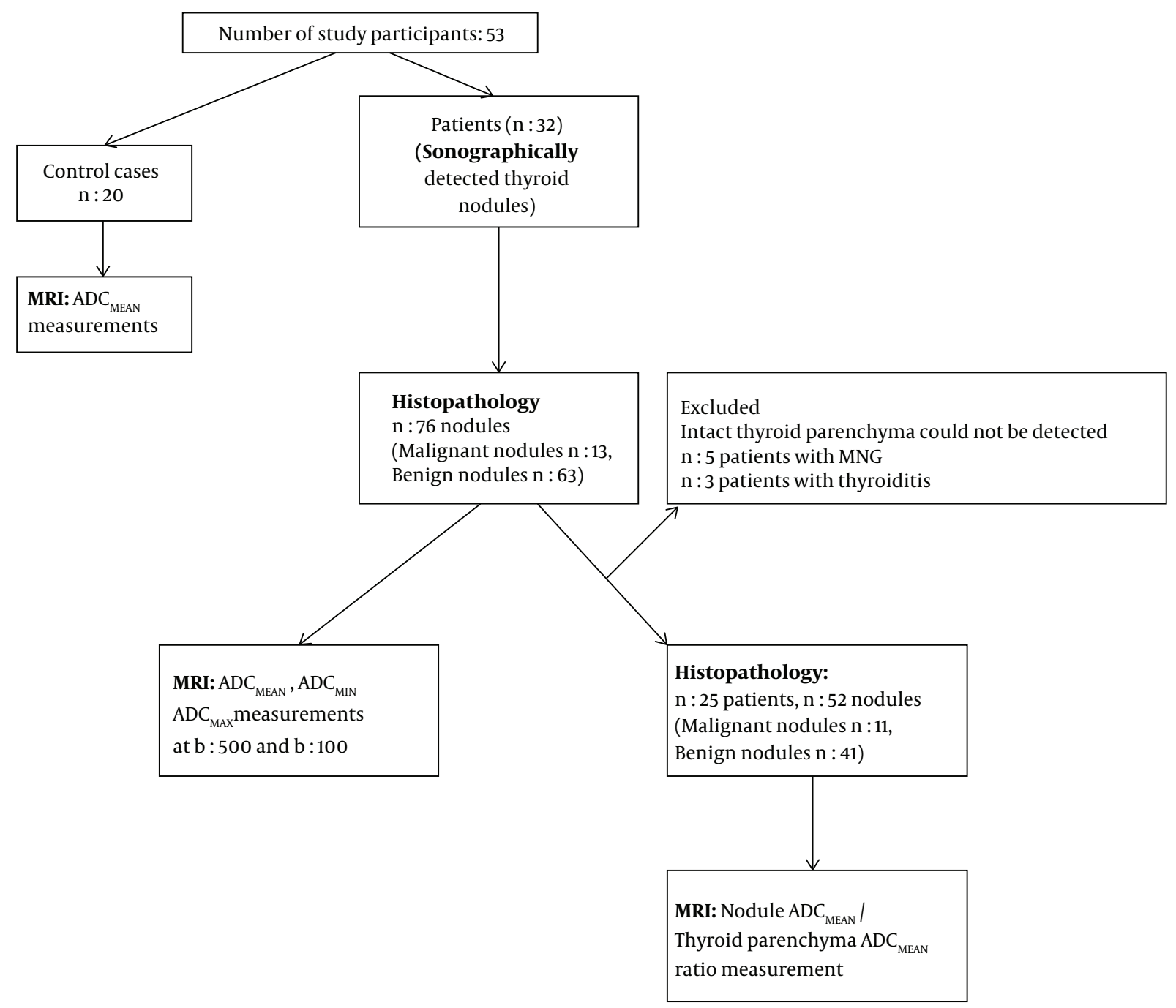

Figure 1. Flowchart of the study. MRI, magnetic resonance imaging; n, number; MNG, multinodular goiter; ADC, apparent diffusion coefficient; MIN, minimum; MAX, maximum

\subsection{Statistical Methods}

Statistical analysis was performed by using SPSS version 15.0 software (SPSS Inc., Chicago, Illinois, USA). In case of more than two independent groups one way analysis of variance test (one way ANOVA) and post-hoc test (Bonferroni) was applied. The difference between two independent groups was investigated by individual difference between groups test (independent samples test) and MannWhitney U test. A P value less than 0.05 was considered statistically significant. A Receiver operating characteristic (ROC) curve analysis was performed to determine the cut off value for ADC for differentiating malignant from benign thyroid nodules. Intraclass correlation coefficients (ICC) were used to determine intraobserver reliability.

\section{Results}

The study population included 32 patients. The total number of nodules analyzed in our study was 76 . Twelve patients had solitary thyroid nodules, 20 patients had multiple nodules. The size of the nodules varied between $1.1 \mathrm{~cm}$ to $6 \mathrm{~cm}$ (average size: $2.7 \mathrm{~cm}$ ). According to the histopathological results, 13 (17.1\%) of the nodules were malignant, 63 (82.8\%) nodules were benign. Histopathological findings of the malignant nodules revealed eight papillary and two medullary cancers, one follicular, one anaplastic and one poorly differentiated carcinoma. The benign nodules were diagnosed as hyperplastic nodules.

The normal thyroid tissue had a mean $\mathrm{ADC}\left(\mathrm{ADC}_{\mathrm{MEAN}}\right)$ 
value of $1.805 \times 10^{-3} \mathrm{~mm}^{2} / \mathrm{s}$ and $1.350 \times 10^{-3} \mathrm{~mm}^{2} / \mathrm{s}$ at b:500 and b:1000, respectively in the control group. The $\mathrm{ADC}_{\mathrm{MEAN}}$ value of thyroid tissue could be measured in 25 patients. The normal thyroid tissue had a $\mathrm{ADC}_{\text {MEAN }}$ value of $1.879 \times$ $10^{-3} \mathrm{~mm}^{2} / \mathrm{s}$ and $1.423 \times 10^{-3} \mathrm{~mm}^{2} / \mathrm{s}$ at b:500 and b:1000, respectively in patients with thyroid nodules. The $\mathrm{ADC}_{\text {MEAN }}$ value of parenchyma in patients and in control groups did not differ significantly at b:500 and b:1000 ( $P>0.05)$ (Table 1). The intraobserver agreement was very good for $\mathrm{ADC}_{\text {MEAN }}$ at b:500 (intraclass correlation coefficient: 0.88 ; $95 \%$ confidence interval (CI), 0.73 - 0.94) and good for $\mathrm{ADC}_{\mathrm{MEAN}}$ at b:1000 (intraclass correlation coefficient 0.71; 95\% CI, 0.22 0.88 ).

The minimum $\mathrm{ADC}\left(\mathrm{ADC}_{\mathrm{MIN}}\right)$, mean $\mathrm{ADC}\left(\mathrm{ADC}_{\mathrm{MEAN}}\right)$, and maximum $\mathrm{ADC}\left(\mathrm{ADC}_{\mathrm{MAX}}\right)$ values of malignant nodules were calculated as $1.092 \times 10^{-3} \mathrm{~mm}^{2} / \mathrm{s}, 1.371 \times 10^{-3} \mathrm{~mm}^{2} / \mathrm{s}$, and $1.692 \times 10^{-3} \mathrm{~mm}^{2} / \mathrm{s}$, respectively at b:500. The $\mathrm{ADC}_{\mathrm{MIN}}$, $\mathrm{ADC}_{\text {MEAN }}$, and $\mathrm{ADC}_{\text {MAX }}$ values of benign nodules were calculated as $1.892 \times 10^{-3} \mathrm{~mm}^{2} / \mathrm{s}, 2.176 \times 10^{-3} \mathrm{~mm}^{2} / \mathrm{s}$, and $2.474 \times$ $10^{-3} \mathrm{~mm}^{2} / \mathrm{s}$, respectively at b:500. The mean ADC values of malignant nodules at b:500 were significantly lower than mean $A D C$ values of benign nodules $(P<0.0001)$.

The $A D C_{\text {MIN }}, A D C_{\text {MEAN }}, A C_{\text {MAX }}$ values of malignant nodules were calculated as $0.789 \times 10^{-3} \mathrm{~mm}^{2} / \mathrm{s}, 1.027 \times 10^{-3}$ $\mathrm{mm}^{2} / \mathrm{s}$, and $1.263 \times 10^{-3} \mathrm{~mm}^{2} / \mathrm{s}$, respectively at b:1000. The $\mathrm{ADC}_{\text {MIN }}, \mathrm{ADC}_{\text {MEAN }}, \mathrm{ADC}_{\text {MAX }}$ values of benign nodules were calculated $1.454 \times 10^{-3} \mathrm{~mm}^{2} / \mathrm{s}, 2.022 \times 10^{-3} \mathrm{~mm}^{2} / \mathrm{s}$, and 1.714 $\times 10^{-3} \mathrm{~mm}^{2} / \mathrm{s}$, respectively at b:1000. The mean ADC values of malignant nodules at $b: 1000$ were significantly lower than mean ADC values of benign nodules $(\mathrm{P}<0.0001)$ (Figures 2 - 4) (Table 2).

Receiver operating characteristic (ROC) curve analysis was performed to detect cut off values differentiating benign from malignant thyroid nodules. The area under the curve (AUC) for b:500 was measured as 0.85 at $\mathrm{ADC}_{\mathrm{MIN}}, 0.85$ at $\mathrm{ADC}_{\text {MEAN }}$, and 0.83 at $\mathrm{ADC}_{\mathrm{MAX}}$ and as 0.91 at $\mathrm{ADC}_{\mathrm{MIN}}, 0.87$ at $\mathrm{ADC}_{\text {MEAN }}$, and 0.86 at $\mathrm{ADC}_{\mathrm{MAX}}$ for b:1000 as shown in Figure 2.

The upper and lower limits of $95 \%$ confidence interval (CI) for b:500 was 0.71-0.99 at $\mathrm{ADC}_{\mathrm{MIN}} ; 0.71-1.00$ at $\mathrm{ADC}_{\text {MEAN }}$; $0.66-1.00$ at $\mathrm{ADC}_{\mathrm{MAX}}$. These limits were detected as 0.82 -1.00 at $\mathrm{ADC}_{\mathrm{MIN}} ; 0.72-1.00$ at $\mathrm{ADC}_{\mathrm{MEAN}}$ and $0.71-1.00$ at $\mathrm{ADC}_{\mathrm{MAX}}$ for b:1000.

Cut off values to differentiate malignant and benign nodules for $\mathrm{ADC}_{\mathrm{MIN}}, \mathrm{ADC}_{\mathrm{MEAN}}$, and $\mathrm{ADC}_{\mathrm{MAX}}$ were determined at b:500 and b:1000. According to the selected cut off values, the calculated sensitivity was $77 \%$. The specificity, positive predictive value, and negative predictive value ranged between $88 \%-100 \%, 58 \%-100 \%$, and $94 \%-95 \%$, respectively (Table 3 ).

The average parenchymal ADC value could be mea- sured in 25 patients and ADC value of 52 nodules was measured in these patients. Eleven (21\%) of these 52 nodules were malignant. Nodule $\mathrm{ADC}_{\mathrm{MEAN}} /$ thyroid parenchyma $\mathrm{ADC}_{\text {MEAN }}$ ratios were calculated. This ratio was significantly lower in malignant nodules compared to the benign nodules at b:500 and b:1000 $(\mathrm{P}<0.0001)$ (Table 4).

ROC curve analysis was performed to detect the power of nodule $\mathrm{ADC}_{\text {MEAN }} /$ thyroid parenchyma $\mathrm{ADC}_{\text {MEAN }}$ ratio to differentiate benign and malignant nodules. The AUC was 0.99 for b:500 and was 1 for b:1000. The upper and lower limits of $95 \% \mathrm{CI}$ was $0.98-1.00$ for b:500, $1.00-1.00$ for b:1000 as shown in Figure 5.

Cut off values to differentiate malignant and benign nodules for the ratio of nodule $\mathrm{ADC}_{\mathrm{MEAN}} /$ thyroid parenchyma $\mathrm{ADC}_{\text {MEAN }}$ were determined at b:500 and b:1000. According to the selected cut off values (0.98 for b:500 and 0.95 for b:1000) the calculated sensitivity and negative predictive value were $100 \%$. The specificity, and positive predictive value ranged between $92 \%-100 \%$, and $79 \%-100 \%$, respectively (Table 5).

\section{Discussion}

Thyroid nodules are frequently detected with the widespread application of sonography (15). However, the malignancy rate of palpable nodules is less than 5\% (2). The primary goal of imaging is to determine the malignant nodules. MRI diffusion characteristics of thyroid lesions may help us to differentiate different types of thyroid nodules.

Diffusion is a random microscopic movement of water molecules. Measurement of diffusion in vivo is now possible with diffusion-weighted MRI and ADC measurements. The hypercellularity within malignant tumors leads to reduction in the diffusion space of water molecules in the extracellular and intracellular space (16-18). In recent years, DWI in the head and neck region and the thyroid gland has gained importance $(2,8-10,13,19-21)$. The malignant thyroid nodules when compared with the benign ones have larger nuclei and an increased number of cell counts resulting in a decreased extracellular matrix (22). Due to these tissue characteristics, there is restriction in movement of water molecules in malignant nodules resulting in findings of restricted diffusion, and low ADC values on DWI $(2,8,10,13)$. The difference in ADC values between benign and malignant nodules on 1.5 Tesla magnets has been demonstrated by other authors. Most of the studies demonstrated that the ADC values of benign thyroid nodules are significantly greater than those of malignant nodules $(2,8,10)$. The $b$ value has an impact on image quality and $\mathrm{ADC}$ measurement. A high $\mathrm{b}$ value image provides 


\begin{tabular}{|c|c|c|c|c|}
\hline Group & & Mean, $\times 10^{-3} \mathrm{~mm}^{2} / \mathrm{s}$ & Standard deviation & Pvalue $^{a}$ \\
\hline Parenchyma ADC $_{\text {MEAN }}$ b50o & & & & $>0.05$ \\
\hline Malignant & & $1.813(1.310-2.300)$ & 0.278 & \\
\hline Control & & $1.805(1.626-2.168)$ & 0.154 & \\
\hline Benign & & $1.954(1.290-2.250)$ & 0.268 & \\
\hline Parenchyma ADC MEAN $_{\text {b100o }}$ & & & & $>0.05$ \\
\hline Malignant & & $1.491(1.040-1.730)$ & 0.249 & \\
\hline Control & & $1.350(1.147-1.711)$ & 0.150 & \\
\hline Benign & & $1.367(1.050-1.720)$ & 0.195 & \\
\hline \multicolumn{5}{|c|}{$\begin{array}{l}\text { Abbreviations: ADC, apparent diffusion coefficient } \\
{ }^{\mathrm{a}} \mathrm{P}<0.05 \text { indicates significant difference. }\end{array}$} \\
\hline Pathology of nodules & Number of nodules & Mean, $\times 10^{-3} \mathrm{~mm}^{2} / \mathrm{s}$ & Standard deviation & Pvalue $^{\mathrm{a}}$ \\
\hline $\mathrm{ADC}_{\text {MIN }}$ b500 & & & & $<0.000$ \\
\hline Malignant & 13 & $1.092(0.481-1.995)$ & 0.554 & \\
\hline Benign & 63 & $1.892(1.273-2.560)$ & 0.284 & \\
\hline $\mathrm{ADC}_{\mathrm{MAX}} \mathbf{b 5 0 0}$ & & & & $<0.000$ \\
\hline Malignant & 13 & $1.692(0.922-2.749)$ & 0.583 & \\
\hline Benign & 63 & $2.474(1.718-3.655)$ & 0.315 & \\
\hline ADC $_{\text {MEAN }}$ b500 & & & & $<0.000$ \\
\hline Malignant & 13 & $1.371(0.706-2.272)$ & 0.545 & \\
\hline Benign & 63 & $2.176(1.505-2.988)$ & 0.285 & \\
\hline $\mathrm{ADC}_{\text {MIN }} \mathbf{b 1 0 0 0}$ & & & & $<0.000$ \\
\hline Malignant & 13 & $0.789(0.391-1.396)$ & 0.359 & \\
\hline Benign & 63 & $1.454(1.005-2.319)$ & 0.266 & \\
\hline $\mathrm{ADC}_{\text {MAX }} \mathrm{b} 1000$ & & & & $<0.000$ \\
\hline Malignant & 13 & $1.263(0.663-2.133)$ & 0.472 & \\
\hline Benign & 63 & $2.022(1.468-3.375)$ & 0.360 & \\
\hline $\mathrm{ADC}_{\text {MEAN }} \mathrm{b1000}$ & & & & $<0.000$ \\
\hline Malignant & 13 & $1.027(0.504-1.724)$ & 0.414 & \\
\hline Benign & 63 & $1.714(1.252-2.954)$ & 0.310 & \\
\hline
\end{tabular}

Abbreviations: ADC, apparent diffusion coefficient; MIN, minimum, MAX, maximum ${ }^{\mathrm{a}} \mathrm{P}<0.05$ indicates significant difference.

\begin{tabular}{|c|c|c|c|c|c|}
\hline & Cut off value, $\times 10^{-3} \mathrm{~mm}^{2} / \mathrm{s}$ & Sensitivity, \% & Specificity, \% & PPV, \% & NPV, \% \\
\hline ADC $_{\text {MIN }}$ b500 & 1.574 & 77 & 88 & 58 & 94 \\
\hline $\mathrm{ADC}_{\text {MEAN }}$ b500 & 1.728 & 77 & 96 & 83 & 95 \\
\hline $\mathrm{ADC}_{\mathrm{MAX}} \mathbf{b 5 0 0}$ & 1.910 & 77 & 98 & 90 & 95 \\
\hline $\mathrm{ADC}_{\text {MIN }} \mathrm{b1000}$ & 1.022 & 77 & 99 & 91 & 95 \\
\hline ADC $_{\text {MEAN }}$ b1000 & 1.238 & 77 & 100 & 100 & 95 \\
\hline $\mathrm{ADC}_{\text {MAX }}$ b1000 & 1.455 & 77 & 100 & 100 & 95 \\
\hline
\end{tabular}

Abbreviations: ADC, apparent diffusion coefficient; MIN, minimum, MAX, maximum; NPV, negative predictive value; PPV, positive predictive value

valuable diffusion data with restricted perfusion and T2weighted effects. However, as the b value increases, the noise increases leading to distortion of the images (23). Image distortion due to susceptibility artifacts is prominant at higher field strength magnets. However, these limita- tions can be overcome by using parallel imaging, smaller voxel size and shorter echo times $(11,24,25)$. In our study, to improve image quality, we performed DWI with parallel imaging (GRAPPA factor: 2), $4 \mathrm{~mm}$ slice thickness and $128 \times 128$ matrix size and obtained images without degra- 


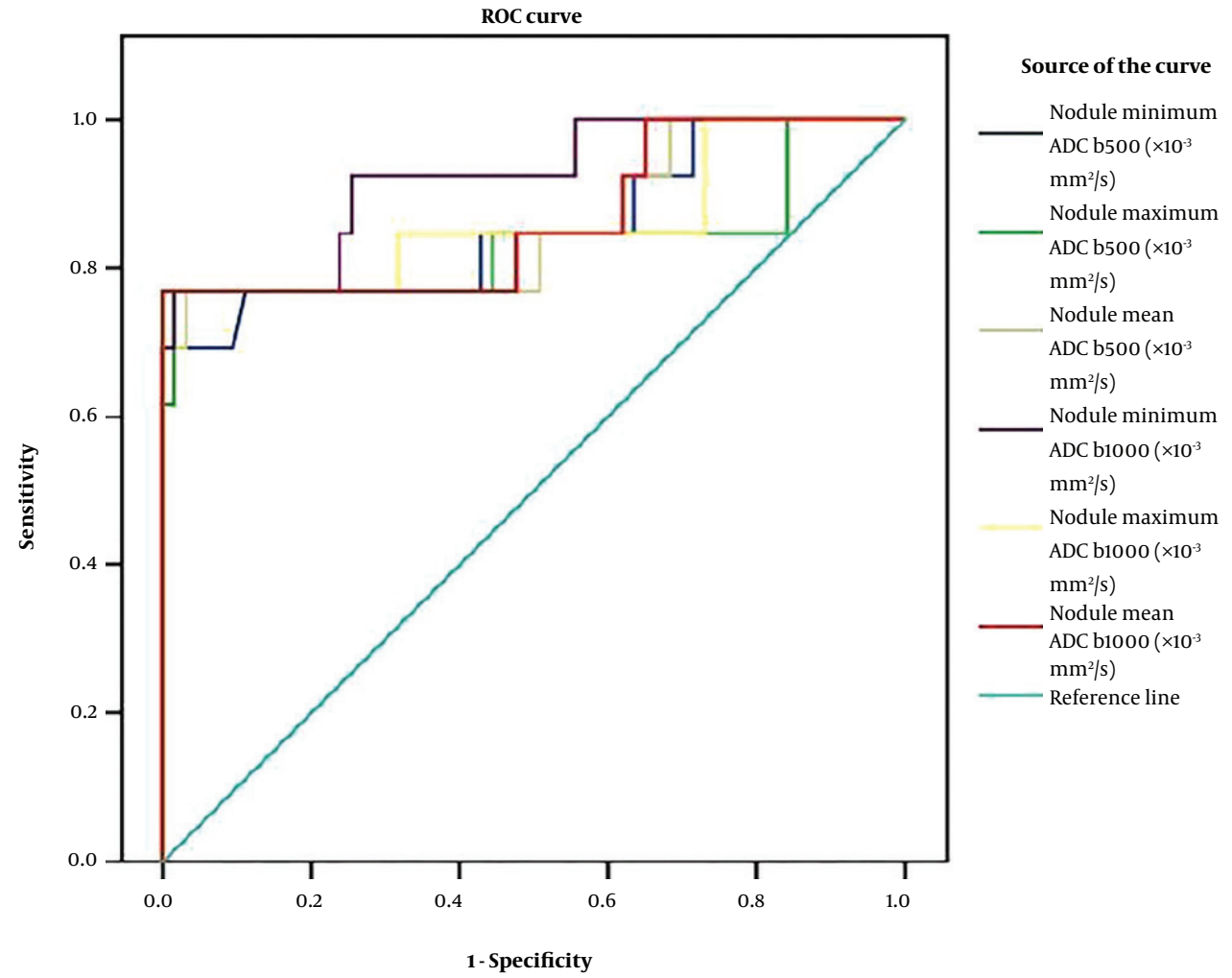

Figure 2. Graph shows receiver operating characteristic (ROC) curves of nodule apparent diffusion coefficients (ADC) [mean, minimum and maximum ADCs] in two b values of 500 and 1000 used for differentiation of benign and malignant nodules.

\begin{tabular}{|c|c|c|c|c|}
\hline Pathologic diagnosis & Number & Nodule $\mathrm{ADC}_{\text {MEAN }} /$ thyroid parenchymal $\mathrm{ADC}_{\text {MEAN }}$ ratio & Standard deviation & Pvalue $^{\mathrm{a}}$ \\
\hline b500 & & & & 0.0001 \\
\hline Malignant & 11 & $0.64(0.35-0.98)$ & 0.202 & \\
\hline Benign & 41 & $1.25(0.93-1.68)$ & 0.200 & \\
\hline b1000 & & & & 0.0001 \\
\hline Malignant & 11 & $0.59(0.29-0.95)$ & 0.163 & \\
\hline Benign & 41 & $1.29(0.96-1.84)$ & 0.199 & \\
\hline
\end{tabular}

Abbreviation: ADC, apparent diffusion coefficient

${ }^{\mathrm{a}} \mathrm{P}<0.05$ indicates significant difference.

Table 5. Sensitivity, Specificity, PPV and NPV of Nodule $\mathrm{ADC}_{\mathrm{MEAN}} /$ Thyroid Parenchyma $\mathrm{ADC}_{\mathrm{MEAN}}$ Cut Off Values Determined at Malignant-Benign Nodule Discrimination

\begin{tabular}{|c|c|c|c|c|c|}
\hline & Cut off value & Sensitivity, \% & Specificity, \% & PPV, \% & NPV, \% \\
\hline Nodule $A_{D C} C_{\text {MEAN }} /$ thyroid parenchyma ADC $_{\text {MEAN }}$ (b500) & 0.98 & 100 & 92 & 79 & 100 \\
\hline Nodule ADC $_{\text {MEAN }} /$ thyroid parenchyma ADC $_{\text {MEAN }}($ b1000) & 0.95 & 100 & 100 & 100 & 100 \\
\hline
\end{tabular}

Abbreviations: ADC, apparent diffusion coefficient; NPV, negative predictive value; PPV, positive predictive value

dation. In literature, there are limited number of studies about thyroid nodules that have been performed on 3 Tesla magnets $(13,14)$. In a recent study conducted by Ilica et al., they used six b values, with the highest b value of 1500 .
The mean ADC values for benign and malignant nodules were $1.548 \times 10^{-3} \mathrm{~mm}^{2} / \mathrm{s}$, and $0.814 \times 10^{-3} \mathrm{~mm}^{2} / \mathrm{s}$ respectively. The ADC values were significantly different among these groups $(\mathrm{P}<0.001)$. Similarly in our study, we used 

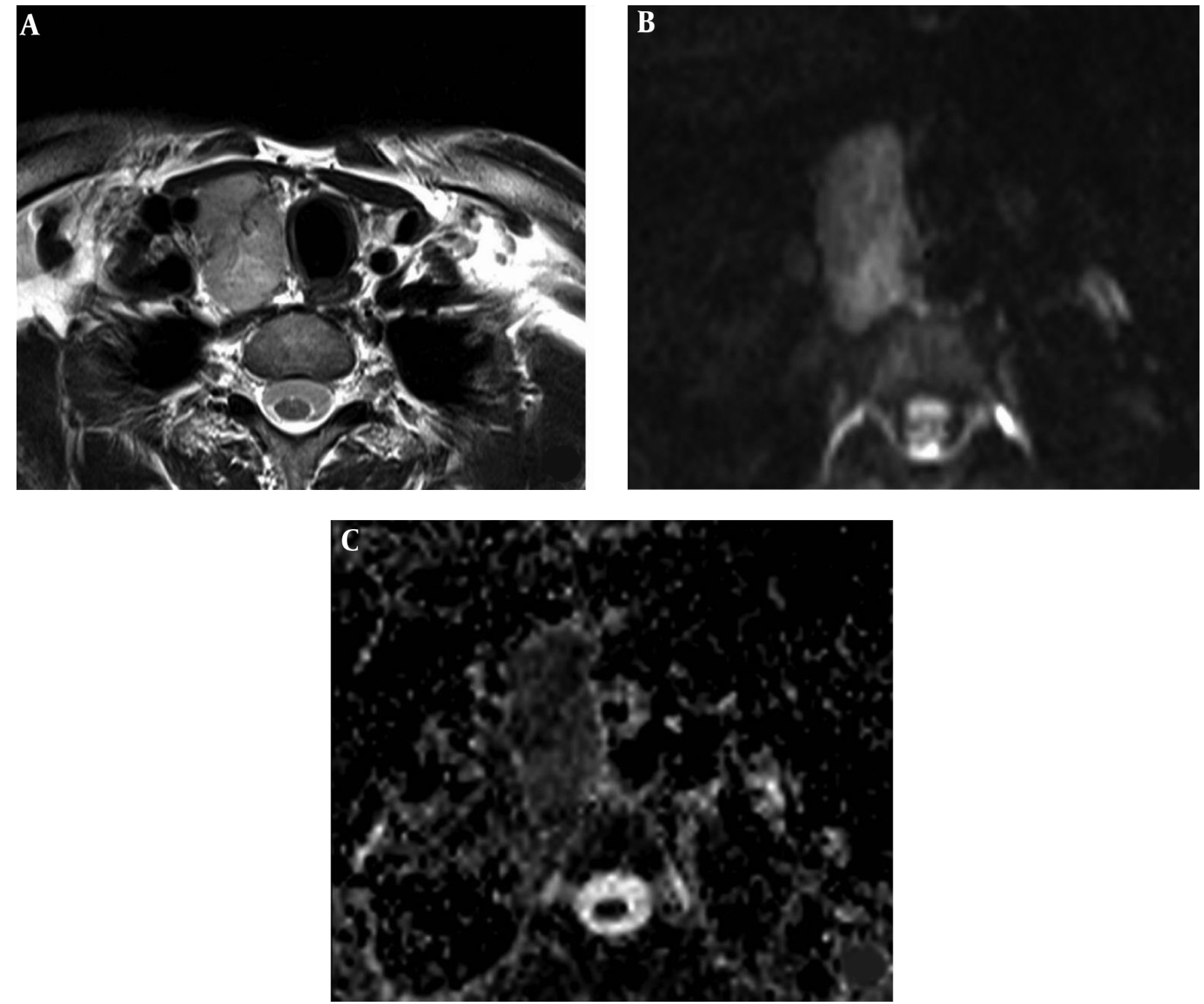

Figure 3. A 42-year-old man with a malignant nodule (histopathologically confirmed as medullary thyroid carcinoma). Axial T2 weighted MR image shows the nodule in the right thyroid lobe (A). The nodule has high signal intensity on diffusion weighted imaging (DWI) at b:1000 (B), and low signal intensity on apparent diffusion coefficient (ADC) map (C) with $\mathrm{ADC}_{\text {MEAN }}$ value of $0.746 \times 10^{-3} \mathrm{~mm}^{2} / \mathrm{s}$. The $\mathrm{ADC}_{\text {MEAN }}$ value of thyroid parenchyma is measured as $1.951 \times 10^{-3} \mathrm{~mm}^{2} / \mathrm{s}$ and the nodule $A D C_{\text {MEAN }} /$ thyroid parenchyma $\mathrm{ADC}_{\mathrm{MEAN}}$ ratio is calculated as 0.38 at b:1000.

high b values (b:500, b:1000) and the ADC values of 63 benign nodules were significantly higher than the 13 malignant nodules at both $b$ levels $(\mathrm{P}<0.000)$. The mean ADC value of the benign nodules was $2.022 \times 10^{-3} \mathrm{~mm}^{2} / \mathrm{s}$ and the mean ADC of the malignant nodules was $1.027 \times 10^{-3}$ $\mathrm{mm}^{2} / \mathrm{s}$ for b:1000 in the present study. Ilicaet al. reported the mean ADC value of the normal thyroid tissue as $1.323 \pm$ $210\left(\times 10^{-3} \mathrm{~mm}^{2} / \mathrm{s}\right)$ in the healthy control group. This finding is similar with the ADC values of our healthy control group at b:1000 $\left(1.350 \pm 150 \times 10^{-3} \mathrm{~mm}^{2} / \mathrm{s}\right)(13)$.

Despite the new automated measurement techniques, $A D C$ values can vary between patients and within patients. For this reason, ADC measurements from unaffected tis- sues of patient groups were compared with each other and with the control group. Calculation of the normalized ADC values can eliminate the imaging related variability $(21,26)$. Bozgeyik et al. checked the normal looking parenchyma of patients with thyroid nodules. There were no significant difference between the ADC values of thyroid tissue in healthy subjects and the patient group with nodules (10). They reported that the thyroid parenchyma ADC values of the patient group can be regarded as a reference as control group (10). We could evaluate the average parencyhmal ADC value in 25 patients. ADC values obtained from the parenchyma fields were confirmed histopathologically as normal in these patients. Therefore, 

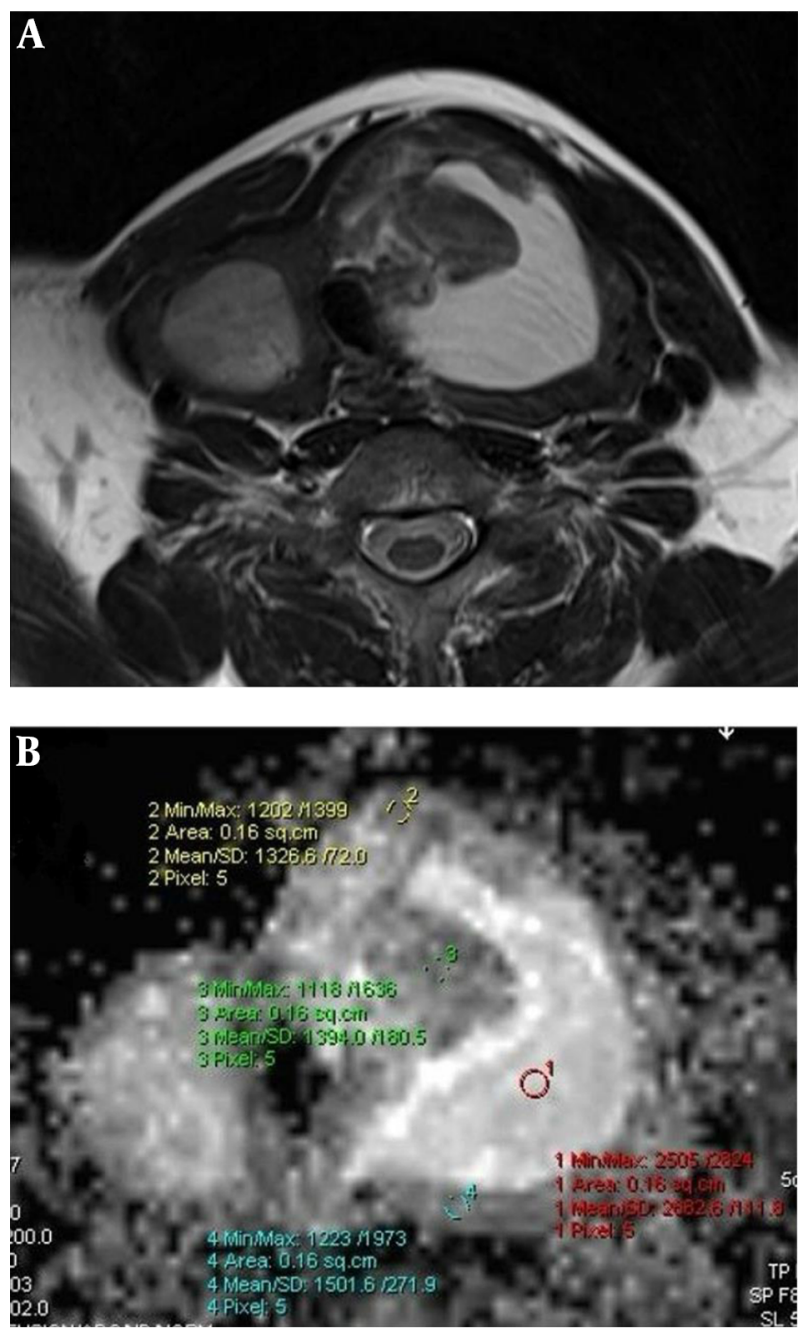

Figure 4. Hyperplastic nodule. Axial T2 (A) weighted MR image shows multiple thyroid nodules in thyroid lobes. The nodule located in the left lobe has a central cystic colloidal component. Measurement of the nodule was performed from the peripheral solid component on apparent diffusion coefficient (ADC) map. ADC map at b:1000 (B) shows the $A D C_{M E A N}$ value of the solid component is $1.407 \times 10^{-3} \mathrm{~mm}^{2} / \mathrm{s}$. The high signal intensity (increased diffusion) of the colloidal component (ADC: $2.682 \times 10^{-3} \mathrm{~mm}^{2} / \mathrm{s}$ ) can also be seen.

we think that the parenchyma ADC values of this patient group can be accepted as a reference for thyroid gland parenchyma. Similar to the study carried out by Bozgeyik et al. (10) in our study, no statistically significant difference was found between the normal parenchyma $\mathrm{ADC}_{\mathrm{MEAN}}$ of the patient and control group at b: 500 and b:1000. When we compared the parenchyma $\mathrm{ADC}_{\mathrm{MEAN}}$ values of the malignant, benign and control groups, we also found no difference between the three groups (Table 1). In our study, nodal $\mathrm{ADC}_{\mathrm{MEAN}} /$ thyroid parenchyma $\mathrm{ADC}_{\mathrm{MEAN}}$ ratios of malignant nodules were significantly lower than be-

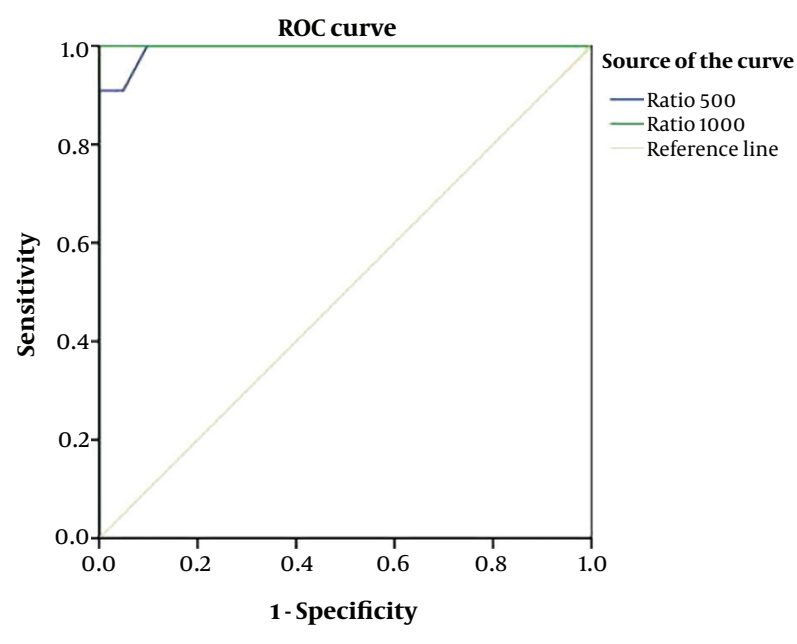

Figure 5. Graph shows receiver operating characteristic (ROC) curve of nodule mean apparent diffusion coefficient $\left(\mathrm{ADC}_{\mathrm{MEAN}}\right.$ )/thyroid parenchyma $\mathrm{ADC}_{\mathrm{MEAN}}$ ratio used for differentiation of benign and malignant nodules. The area under the curve (AUC) was 0.99 for b:500 and was 1 for b:1000.

nign nodules in both b: 500 and b:1000 values and there was no overlap between these groups. In the analysis of the ROC curve showing the power of the $\mathrm{ADC}_{\mathrm{MEAN}} /$ thyroid parenchyma $\mathrm{ADC}_{\mathrm{MEAN}}$ ratio to differentiate benign and malignant nodules, the area under the curve was 0.99 for b:500 and 1 for b:1000. Sensitivity at thresholds determined by the curve was found to be $100 \%$ for both b:500 and b:1000 values. That is, the ADC ratio of all malignant nodules is below 0.98 at b:500 and below 0.95 at b:1000 and the specificity is $92 \%$ and $100 \%$ respectively at $\mathrm{b}: 500, \mathrm{~b}: 1000$. According to these results, the use of the nodal $\mathrm{ADC}_{\mathrm{MEAN}} /$ thyroid parenchyma $\mathrm{ADC}_{\mathrm{MEAN}}$ ratio in distinction of malignant-benign thyroid nodules appears to be a very sensitive and specific method. The limitation of this method is multinodular goiter cases in which measurement of intact thyroid parenchyma may be difficult. Mutlu et al. normalized their measurements using the spine as a reference (21). However, the spinal cord is surrounded by spinal osseous elements, which can lead difficulty in measurements. According to our findings, the intact thyroid tissue of the patient can be used for normalization issues. Therefore, combination of normalized ADC values might be helpful in the interpretation of thyroid nodules and might determine the optimal ADC ratio for quantitative evaluation.

There are several limitations of the study. First, evaluation of nodules below $1 \mathrm{~cm}$ was not included in the study. Therefore, it is necessary to determine the accuracy of 3 Tesla diffusion MRI findings in this group of patients as well. Second, the sample size of malignant nod- 
ules was relatively small in our study group. A larger population would probably strengthen these findings and provide more information.

In conclusion, the findings of our study show that $\mathrm{ADC}$ values obtained with high $\mathrm{b}$ values at $3 \mathrm{~T}$ are beneficial in differentiation of benign and malignant thyroid nodules. Measurement of nodule $\mathrm{ADC}_{\mathrm{MEAN}} /$ thyroid parenchyma $\mathrm{ADC}_{\mathrm{MEAN}}$ ratio is a valuable adjunctive tool. Further large scale studies are mandatory to predict the clinical impact of $3 \mathrm{~T}$ DWI.

\section{Footnotes}

Authors' Contributions: Study concept and design: Pınar Karakan Öztürk, Selen Bayraktaroglu, and Naim Ceylan; acquisition of images: Pınar Karakan Öztürk; surgical procedures: Gökhan İçöz and Özer Makay; pathologic examination: Yeșim Ertan; analysis and interpretation of data: Pınar Karakan Öztürk, and Selen Bayraktaroglu; critical revision of the manuscript for important intellectual content: Selen Bayraktaroglu and Pınar Karakan Öztürk; administrative, technical, and material support: Naim Ceylan

Conflict of Interests: None declared.

Ethical Approval: The study protocol was approved by the local ethics committee.

Financial Disclosure: None declared.

Funding/Support: None declared.

\section{References}

1. Reading CC, Charboneau JW, Hay ID, Sebo TJ. Sonography of thyroid nodules: A "classic pattern" diagnostic approach. Ultrasound Q. 2005;21(3):157-65. doi:10.1097/01.ruq.0000174750.27010.68. [PubMed: 16096611].

2. Erdem G, Erdem T, Muammer H, Mutlu DY, Firat AK, Sahin I, et al. Diffusion-weighted images differentiate benign from malignant thyroid nodules. J Magn Reson Imaging. 2010;31(1):94-100. doi: 10.1002/jmri.22000. [PubMed: 20027577].

3. Singer PA, Cooper DS, Daniels GH, Ladenson PW, Greenspan FS, Levy EG, et al. Treatment guidelines for patients with thyroid nodules and well-differentiated thyroid cancer. American Thyroid Association. Arch Intern Med. 1996;156(19):2165-72. doi: 10.1001/archinte.1996.00440180017002. [PubMed: 8885814].

4. Rojeski MT, Gharib H. Nodular thyroid disease. Evaluation and management. $N$ Engl J Med. 1985;313(7):428-36. doi: 10.1056/NEJM198508153130707. [PubMed: 3894966].

5. Abboud B, Allam S, Chacra LA, Ingea H, Tohme C, Farah P. Use of fineneedle aspiration cytology and frozen section in the management of nodular goiters. Head Neck. 2003;25(1):32-6. doi:10.1002/hed.10184. [PubMed: 12478541].

6. Hamming JF, Vriens MR, Goslings BM, Songun I, Fleuren GJ, van de Velde CJ. Role of fine-needle aspiration biopsy and frozen section examination in determining the extent of thyroidectomy. World J Surg. 1998;22(6):575-9. discussion 579-80. doi: 10.1007/s002689900437. [PubMed: 9597931].
7. Warach S, Chien D, Li W, Ronthal M, Edelman RR. Fast magnetic resonance diffusion-weighted imaging of acute human stroke. Neurology. 1992;42(9):1717-23. doi: 10.1212/wnl.42.9.1717. [PubMed: 1513459].

8. Razek AA, Sadek AG, Kombar OR, Elmahdy TE, Nada N. Role of apparent diffusion coefficient values in differentiation between malignant and benign solitary thyroid nodules. AJNR Am J Neuroradiol. 2008;29(3):563-8. doi: 10.3174/ajnr.A0849. [PubMed: 18039755].

9. Schueller-Weidekamm C, Kaserer K, Schueller G, Scheuba C, Ringl H, Weber M, et al. Can quantitative diffusion-weighted MR imaging differentiate benign and malignant cold thyroid nodules? Initial results in 25 patients. AJNR Am J Neuroradiol. 2009;30(2):417-22. doi: 10.3174/ajnr.A1338. [PubMed: 18945798].

10. Bozgeyik Z, Coskun S, Dagli AF, Ozkan Y, Sahpaz F, Ogur E. Diffusion-weighted MR imaging of thyroid nodules. Neuroradiology. 2009;51(3):193-8. doi: 10.1007/s00234-008-0494-3. [PubMed: 19165474].

11. Srinivasan A, Dvorak R, Perni K, Rohrer S, Mukherji SK. Differentiation of benign and malignant pathology in the head and neck using 3T apparent diffusion coefficient values: Early experience. AJNR Am J Neuroradiol. 2008;29(1):40-4. doi:10.3174/ajnr.A0743. [PubMed:17921228].

12. King AD, Ahuja AT, Yeung DK, Fong DK, Lee YY, Lei KI, et al. Malignant cervical lymphadenopathy: Diagnostic accuracy of diffusionweighted MR imaging. Radiology. 2007;245(3):806-13. doi: 10.1148/radiol.2451061804. [PubMed:17911539].

13. Ilica AT, Artas H, Ayan A, Gunal A, Emer O, Kilbas Z, et al. Initial experience of 3 tesla apparent diffusion coefficient values in differentiating benign and malignant thyroid nodules. J Magn Reson Imaging. 2013;37(5):1077-82. doi:10.1002/jmri.23913. [PubMed: 23148044].

14. Hao Y, Pan C, Chen W, Li T, Zhu W, Qi J. Differentiation between malignant and benign thyroid nodules and stratification of papillary thyroid cancer with aggressive histological features: Whole-lesion diffusion-weighted imaging histogram analysis. J Magn Reson Imaging. 2016;44(6):1546-55. doi:10.1002/jmri.25290. [PubMed: 27093648].

15. Brander A, Viikinkoski P, Nickels J, Kivisaari L. Thyroid gland: US screening in a random adult population. Radiology. 1991;181(3):683-7. doi: 10.1148/radiology.181.3.1947082. [PubMed: 1947082].

16. Wang J, Takashima S, Takayama F, Kawakami S, Saito A, Matsushita T, et al. Head and neck lesions: Characterization with diffusionweighted echo-planar MR imaging. Radiology. 2001;220(3):621-30. doi: 10.1148/radiol.2202010063. [PubMed: 11526259].

17. Kartalis N, Lindholm TL, Aspelin P, Permert J, Albiin N. Diffusionweighted magnetic resonance imaging of pancreas tumours. Eur Radiol. 2009;19(8):1981-90. doi: 10.1007/s00330-009-1384-8. [PubMed: 19308414].

18. Koh DM, Collins DJ. Diffusion-weighted MRI in the body: Applications and challenges in oncology. AJR Am J Roentgenol. 2007;188(6):1622-35. doi: 10.2214/AJR.06.1403. [PubMed: 17515386].

19. Eida S, Sumi M, Sakihama N, Takahashi H, Nakamura T. Apparent diffusion coefficient mapping of salivary gland tumors: prediction of the benignancy and malignancy. AJNR Am J Neuroradiol. 2007;28(1):116-21. [PubMed: 17213436].

20. Abdel Razek AA, Soliman NY, Elkhamary S, Alsharaway MK, Tawfik A. Role of diffusion-weighted MR imaging in cervical lymphadenopathy. Eur Radiol. 2006;16(7):1468-77. doi: 10.1007/s00330-005-0133-X. [PubMed: 16557366].

21. Mutlu H, Sivrioglu AK, Sonmez G, Velioglu M, Sildiroglu HO, Basekim $\mathrm{CC}$, et al. Role of apparent diffusion coefficient values and diffusionweighted magnetic resonance imaging in differentiation between benign and malignant thyroid nodules. Clin Imaging. 2012;36(1):1-7. doi: 10.1016/j.clinimag.2011.04.001. [PubMed: 22226435].

22. Schueller-Weidekamm C, Schueller G, Kaserer K, Scheuba C, Ringl H, Weber M, et al. Diagnostic value of sonography, ultrasound-guided fine-needle aspiration cytology, and diffusion-weighted MRI in the 
characterization of cold thyroid nodules. Eur J Radiol. 2010;73(3):53844. doi: 10.1016/j.ejrad.2008.12.013. [PubMed: 19195809].

23. Le Bihan D, Breton E, Lallemand D, Aubin ML, Vignaud J, Laval-Jeantet M. Separation of diffusion and perfusion in intravoxel incoherent motion MR imaging. Radiology.1988;168(2):497-505. doi: 10.1148/radiology.168.2.3393671. [PubMed: 3393671].

24. Heidemann RM, Ozsarlak O, Parizel PM, Michiels J, Kiefer B, Jellus $\mathrm{V}$, et al. A brief review of parallel magnetic resonance imaging. Eur Radiol. 2003;13(10):2323-37. doi: 10.1007/s00330-003-1992-7. [PubMed:
12942278].

25. Schmitz BL, Aschoff AJ, Hoffmann MH, Gron G. Advantages and pitfalls in 3T MR brain imaging: a pictorial review. AJNR Am J Neuroradiol. 2005;26(9):2229-37. [PubMed: 16219827].

26. Hein PA, Eskey CJ, Dunn JF, Hug EB. Diffusion-weighted imaging in the follow-up of treated high-grade gliomas: tumor recurrence versus radiation injury. AJNR Am J Neuroradiol. 2004;25(2):201-9. [PubMed: 14970018]. 